\title{
ANALYSIS THE EFFECTS OF DIFFERENT TYPES OF TOOL ON METAL SPINNING PROCESS
}

\author{
Sandeep Kamboj ${ }^{1}$, Bharat Atray ${ }^{2}$, Neeraj Kumar ${ }^{3}$ \\ Department of Mechanical Engineering, Maharishi Markandeshwar Group of Institutions (Ramba) Karnal, India \\ Assistant Professor, Department of Mechanical Engineering
}

\begin{abstract}
Metal Spinning is process of sheet metal on the lathe machine is an excellent means for quickly prototyping round hollow metal shapes. A uniform force is applied on sheet metal by rotating the metal and its mandrel at very high speed, thus the sheet metal is deformed evenly without any type of defect like wrinkling or warble. In this paper presenting the manufacturing the hollow cone and frustum form a thin circular disc through step development (120deg. - 90deg.) of mandrel while volume of circular disc remains same. It is analyzed by experiments that the surface finish is poor by applied the feed by cross slide. Achieved the better surface finish by feed rate kept constant with using the copping attachment on lathe.
\end{abstract}

Keywords: Sheet Metal Forming, Metal Spinning, Cad Modelling, Tool Design, Mandrel Design $* * *$

\section{INTRODUCTION}

Metal spinning is a chip-less forming process in which produce hollow, axially symmetric sheet metal components stated by Brown, J. (1998). Spinning also has the possibility of producing parts that could not be deep drawn stated by Eamonn Quigleya, John Monaghan (2000). Spinning process consists of clamping a metal sheet against a mandrel and tail stock on a spinning lathe, and gradually forming the sheet onto the mandrel surface by a roller, either in a single step or by multiple steps. Spinning process is capable to forming component from diameters range $3 \mathrm{~mm}$ to $10 \mathrm{~m}$, and thicknesses of $0.4-25 \mathrm{~mm}$. Automotive and aerospace industries, art objects, musical instruments and kitchenware are produced by spinning process. Components for jet engines and turbines, radar reflectors, satellite nose cones as well as cymbals and domestic utensils are some examples of spinning process as explained by various researchers. During the metal spinning process, both the mandrel and blank are rotated and the spinning tool contacts the metal sheet, progressively induces a change in the shape of metal sheet according to the mandrel profile. The total forming forces can be reduced efficiently as compared to conventional press forming, as the tool is moved locally on the work-piece. In spinning process, the shape can be changed with simple tools and lesser load and also it reduces the cost of production. Spinning process produces the components with high surface finish and better mechanical properties.

Yao Jianguo, and Murata Makoto (2002) showed that the thickness strain, the spinning force, the twisting angle and the surface roughness increase as the tube diameter reduces and the spinning pitch increases. Chul Kim et al. (2003) derived velocity fields and strain rates from considering the adequate deformation mode and the contact factor is introduced to obtain the lower upper-bound power. Makoto Murata et al. (2005) were invented new Computer Numerical Control (CNC) spinning machine, which has roller tools with heaters. The heated tools heat and form the magnesium tubes into various shapes by the spinning. M. Zhan et al. (2007) showed that the growing of the roller feed rate, all components and resultant force of spinning force, wall thickness and its evenness increase, but the shape and size precision decreases. The roller feed rate has an obvious effect on the practical deviation state: with the growing of the roller feed rate, the practical deviation state changes from mixed-deviation to under-deviation, just such characteristic leads the flange to bend backward, keep vertical, or wrinkle. BAI Qian et al. (2008) showed that the FE model considering elastic deformation can not only be used to analyze the workpiece springback in the complex spinning process, but also serve as a significant guide to study the local deformation mechanism. Ichiro Shimizu (2010) was developed a asynchronous spinning machine; in this case, the mandrel motion, mandrel feed, and roller feed were synchronized by pulse control. Asymmetric sheet metal forming was successfully carried out by using the developed synchronous spinning method. L. Wang, and $\mathrm{H}$. Long (2011) showed that the concave path produces highest tool forces among these four roller path profiles. Using the concave roller path tends to cause higher reductions of wall thickness of the spun part and using the convex roller path helps to maintain the original wall thickness unchanged. L. Wang, and H. Long (2011) was developed a Finite Element (FE) analysis model based on a 5-pass conventional spinning experiment. The explicit Finite Element solution method has been used to model this multi-pass spinning process. Effects of mass scaling and reduced integration linear element used in 
the FE simulation have been evaluated by using various energy histories obtained from the FE analysis.

\section{DESIGN AND EXPERIMENTAL PROCEDURE}

Design and Development of Mandrel:- Mandrel is a specific type of die which is female part of die and tool is male part used to spin on lathe machine. There are no allowances in spinning as casting because the outer surfaces of mandrel give the finish to the inner surface of the job or work piece. The outer surface of the mandrel is stick with inner surface of the job due to high pressure.

Specifications for mandrel are as following
a. Diameter of mandrel: - $100 \mathrm{~mm}$
b. Angle of the mandrel : $-45 \mathrm{~mm}$
c. Flat seat of mandrel: $-35 \mathrm{~mm}$
d. Minimum diameter of mandrel: $-90 \mathrm{~mm}$
e. Material:- Mild Steel

\subsection{Design and Development of Tools}

\subsubsection{Roller Wheel Tool}

Roller wheel tool is generally used for thick or soft material due to this the surface finish of the final product can be increased which is depends upon the worker skills.

Specifications for roller wheel tool

1. Diameter of Roller Wheel : $-50 \mathrm{~mm}$

2. Thickness of Roller Wheel :- $11 \mathrm{~mm}$

3. Side step of Wheel :- $2 \mathrm{~mm}$

4. Hole for center pin : $-8.5 \mathrm{~mm}$

5. Curve radius : $-5.5 \mathrm{~mm}$

6. Lengthof tool: $-250 \mathrm{~mm}$

7. Diameter of tool: $-32 \mathrm{~mm}$

8. Length of slot: $-50 \mathrm{~mm}$

9. Thickness of slot: $-11.1 \mathrm{~mm}$

10. Length of adjustment plate: $-150 \mathrm{~mm}$

11. No of holes for adjustment: -6

12. Distance between each hole : $-25 \mathrm{~mm}$

13. Diameter of hole for adjustment: $-10 \mathrm{~mm}$

\subsubsection{Tapper Roller Wheel Tool}

This type of tool is used for complex shapes and for sharp turns which are very difficult for forming of metal.

Specifications for tapper roller wheel tool

1. Diameter of Tapper Roller Wheel : - $50 \mathrm{~mm}$

2. Thickness of Tapper Roller Wheel :- $11 \mathrm{~mm}$

3. Side step of Wheel: $-2 \mathrm{~mm}$

4. Hole for center pin : $-8.5 \mathrm{~mm}$

5. Tapper angle: $-45^{0}$

6. Lengthof tool: $-250 \mathrm{~mm}$

7. Diameter of tool: $-32 \mathrm{~mm}$
8. Length of slot: $-50 \mathrm{~mm}$

9. Thickness of slot: $-11.1 \mathrm{~mm}$

10. Length of adjustment plate: $-150 \mathrm{~mm}$

11. No of holes for adjustment: -6

12. Distance between each hole : $-25 \mathrm{~mm}$

13. Diameter of hole for adjustment: $-10 \mathrm{~mm}$

\subsubsection{Sheep's Nose Duck Tool}

This type of tool is used for deform the metal form its initial position to further work.

Specifications for Sheep's nose duck tool: -

1. Diameter of rod: $-15 \mathrm{~mm}$

2. Angle maintain : $-55 \mathrm{~mm}$

3. Length of tool: $-900 \mathrm{~mm}$

\subsection{Design and Development of Supports}

Tail stock support is use to hold or support the metal sheet in front of mandrel. Generally the material of tail support is soft as compare of material of sheet. In this experimental work mild steel is use as material for development of tail stock support.

Specification for tail stock support

1. Diameter of Support: $-32 \mathrm{~mm}$

2. Length of Support: $-30 \mathrm{~mm}$

3. Center drill : - $10 \mathrm{~mm}$

\subsubsection{Spinning Procedure}

Hold mandrel in three jaws chuck of lathe machine. Then set the metal sheet in between the mandrel and tail stock support as show in fig 5 . Firstly presses the metal sheet with bigger tail stock for better grip for small support so that the nose of the cone and frustum can be maintain and the nearest portion of the tail stock can be spun. After the complication of first pass of spinning which is given by cross slide manually as shown in fig 1 .

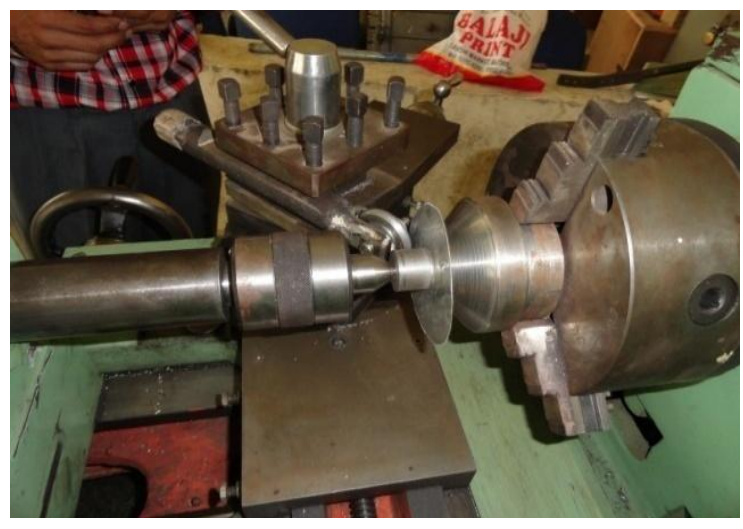

Fig 1: Arrangement of Mandrel and spinning tool 


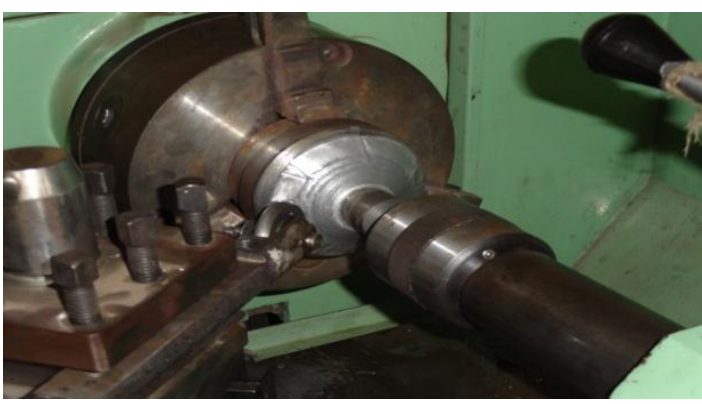

Fig 2: Spinning Procedure

\subsubsection{Experimental Design Strategy}

In the Taguchi's method the results of the experiments are analyzed to achieve one or more of the following objectives:

- To establish the best or the optimum condition for a product or process

- To estimate the contribution of individual parameters and interactions

- To estimate the response under the optimum condition

Table1: Force readings, measured by dynamometer

\begin{tabular}{|c|c|c|c|}
\hline \multicolumn{4}{|c|}{ Force Measurement Readings } \\
\hline Sr. No. & 1 & 2 & 3 \\
\hline 1 & 12.35 & 12.43 & 13.06 \\
\hline 2 & 12.66 & 13.23 & 13.34 \\
\hline 3 & 13.24 & 13.67 & 13.52 \\
\hline 4 & 11.35 & 11.76 & 12.07 \\
\hline 5 & 12.52 & 12.29 & 12.83 \\
\hline 6 & 9.82 & 10.23 & 10.15 \\
\hline 7 & 11.17 & 11.65 & 11.43 \\
\hline 8 & 10.34 & 10.23 & 10.12 \\
\hline 9 & 9.28 & 9.43 & 10.16 \\
\hline
\end{tabular}

Table 1 shows the three readings of feed force for every experiment. This also shows that total 9 experiments have been conducted for feed force measurement.
Table 2 Spinning Parameters and Their Levels

\begin{tabular}{|c|c|c|c|c|}
\hline S.No. & $\begin{array}{c}\text { Input } \\
\text { parameters }\end{array}$ & 1 & 2 & 3 \\
\cline { 3 - 5 } 1. & $\begin{array}{c}\text { Spinning } \\
\text { Tool Shape }\end{array}$ & $\begin{array}{c}\text { Sheep's } \\
\text { Nose } \\
\text { Duck ( } \\
\text { T1) }\end{array}$ & $\begin{array}{c}\text { Large } \\
\text { Roller } \\
\text { Wheel(T2) }\end{array}$ & $\begin{array}{c}\text { Taper } \\
\text { Roller } \\
\text { wheel(T3) }\end{array}$ \\
\hline 2. & $\begin{array}{c}\text { Rotating } \\
\text { Speed (rpm) }\end{array}$ & 125 & 250 & 465 \\
\hline 3. & $\begin{array}{c}\text { Feed Rate } \\
\text { (mm/rev) }\end{array}$ & 0.04 & 0.8 & 0.1 \\
\hline
\end{tabular}

The table 2 shows the three levels of spinning tool shape, rotating speed of mandrel in rpm and tool feed rate in $\mathrm{mm} / \mathrm{rev}$.

Table 3: $\mathrm{L}_{9}\left(3^{3}\right)$ Taguchi orthogonal array design of experiments

\begin{tabular}{|c|c|c|c|}
\hline \multirow{2}{*}{$\begin{array}{l}\text { Experiment } \\
\text { No. }\end{array}$} & \multicolumn{3}{|c|}{ Parameters } \\
\cline { 2 - 4 } & $\begin{array}{c}\text { Tool } \\
\text { shape }\end{array}$ & speed(rpm) & $\begin{array}{c}\text { Feed } \\
(\mathrm{mm} / \mathrm{rev} \text {. })\end{array}$ \\
\hline 1 & 1 & 1 & 1 \\
\hline 2 & 1 & 2 & 2 \\
\hline 3 & 1 & 3 & 3 \\
\hline 4 & 2 & 1 & 2 \\
\hline 5 & 2 & 2 & 3 \\
\hline 6 & 2 & 3 & 1 \\
\hline 7 & 3 & 1 & 3 \\
\hline 8 & 3 & 2 & 1 \\
\hline 9 & 3 & 3 & 2 \\
\hline
\end{tabular}


Table 4: Results of L9 orthogonal array design of experiments

\begin{tabular}{|c|c|c|c|c|c|c|c|c|}
\hline \multirow[b]{2}{*}{ S.No. } & \multirow{2}{*}{$\begin{array}{c}\text { Shape of } \\
\text { Tool }\end{array}$} & \multirow[b]{2}{*}{ Speed } & \multirow[b]{2}{*}{ Feed } & \multicolumn{3}{|c|}{ Force } & \multirow[b]{2}{*}{ Mean1 FF } & \multirow[b]{2}{*}{ SNRA } \\
\hline & & & & FF1 & FF2 & FF3 & & \\
\hline 1 & $\mathrm{~T} 1$ & 125 & 0.04 & 12.35 & 12.43 & 13.06 & 12.6133 & $\begin{array}{c}- \\
22.0193\end{array}$ \\
\hline 2 & $\mathrm{~T} 1$ & 250 & 0.8 & 12.66 & 13.23 & 13.34 & 13.0767 & 22.3322 \\
\hline 3 & $\mathrm{~T} 1$ & 465 & 0.1 & 13.24 & 13.67 & 13.52 & 13.4767 & $\begin{array}{c}- \\
22.5924 \\
\end{array}$ \\
\hline 4 & $\mathrm{~T} 2$ & 125 & 0.8 & 11.35 & 11.76 & 12.07 & 11.7267 & $21 . \overline{3862}$ \\
\hline 5 & $\mathrm{~T} 2$ & 250 & 0.1 & 12.52 & 12.29 & 12.83 & 12.5467 & 21.9719 \\
\hline 6 & $\mathrm{~T} 2$ & 465 & 0.04 & 9.82 & 10.23 & 10.15 & 10.0667 & 20.0591 \\
\hline 7 & T3 & 125 & 0.1 & 11.17 & 11.65 & 11.43 & 11.4167 & $\begin{array}{c}- \\
21.1521 \\
\end{array}$ \\
\hline 8 & T3 & 250 & 0.04 & 10.34 & 10.23 & 10.12 & 10.23 & $\begin{array}{c}- \\
20.1978 \\
\end{array}$ \\
\hline 9 & $\mathrm{~T} 3$ & 465 & 0.8 & 9.28 & 9.43 & 10.16 & 9.6233 & $\begin{array}{c}- \\
19.6734\end{array}$ \\
\hline
\end{tabular}

Table 4: represents the results obtained during spinning on $\mathrm{Al}$ sheets. It represents the measured value of Force, mean of force, and $\mathrm{S} / \mathrm{N}$ ratio. The spinning results i.e. developed force and mean of force, $\mathrm{S} / \mathrm{N}$ ratio results were obtained at variation of spinning tools ( Nose duck tool, Larger roller wheel tool, and Taper roller wheel tool), Speed ( 125, 250, and $465 \mathrm{rpm}$ ) and feed $(0.04,0.1$, and $0.8 \mathrm{~mm} / \mathrm{rev}$.)

\section{RESULTS}

There are many type of defect produce in the forming of cone with the help of spinning process when providing feed motion manually. There are shearing takes place in the sheet due to hard material of tail stock and high rpm of machine. A set of 80 experiments are performed to get finished product. The main defect produce in spinning process is shearing of cone tip which is a curve of $2.5 \mathrm{~mm}$ radius with tail stock support. Spinning process is done on aluminum sheets of thickness about $0.5 \mathrm{~mm}, 1.00 \mathrm{~mm}, 1.5 \mathrm{~mm}$, and $2.00 \mathrm{~mm}$ thick.

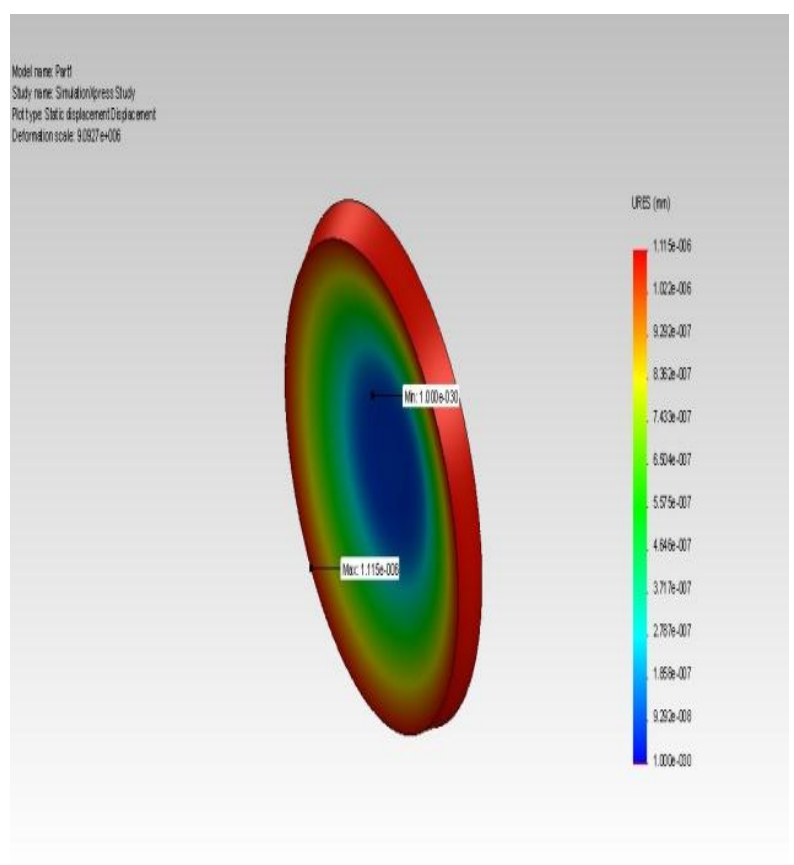

Fig 3: Analysis of forces on aluminium circular sheet 


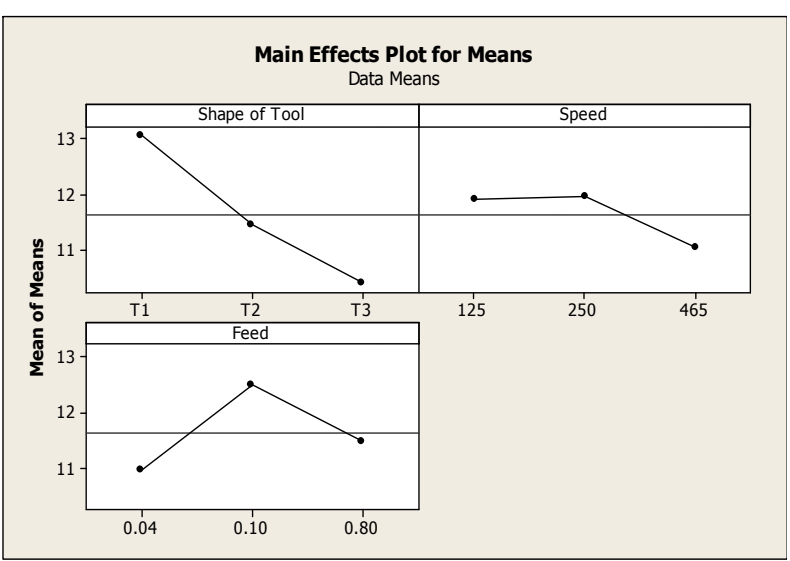

Fig.4: Effects of various parameters on mean of forces.

Figure 4: shows the effect of various parameters of spinning on force such as tool shape, speed and feed. It is observed that by changing tool $\mathrm{T} 1$ to $\mathrm{T} 2$, the required feed force is decreased also when changes from $\mathrm{T} 2$ to $\mathrm{T} 3$ the developed force is further decreased. It is noted that required feed force is minimum at T3.It also shows that when speed changes from $125 \mathrm{rpm}$ to $250 \mathrm{rpm}$, the required feed force is decreased if speed changes from $250 \mathrm{rpm}$ to $465 \mathrm{rpm}$ the required feed force is decreased rapidly this means required feed force is minimum at the speed of $465 \mathrm{rpm}$. It also shows that when feed is changing from $0.04 \mathrm{~mm} / \mathrm{rev}$. to $0.10 \mathrm{~mm} / \mathrm{rev}$. the required feed force goes up and when feed is changing from $0.10 \mathrm{~mm} / \mathrm{rev}$. to $0.80 \mathrm{~mm} / \mathrm{rev}$. the required feed force goes down. It is noted that the force is minimum at feed 0.04 $\mathrm{mm} / \mathrm{rev}$.

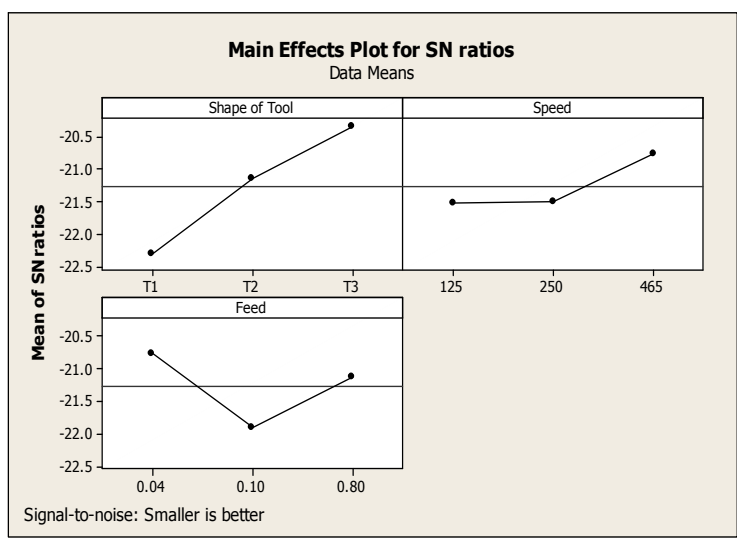

Fig. 5: Effects of various parameters on SN Ratios.

Figure 5: shows the effect of various parameters of spinning on signal to noise ratio such parameters are tool shape, speed and feed. This fig. shows that when tool changes from T1 to $\mathrm{T} 2$, the SN Ratio increases and when tool changes from $\mathrm{T} 2$ to T3, the SN Ratio increases even further. It is noted that at tool T3, SN Ratio have max. value and hence tool T3 is best. The fig shows that when speed changes from $125 \mathrm{rpm}$ to $250 \mathrm{rpm}$, the value of SN Ratio increases and when speed changes from $250 \mathrm{rpm}$ to $465 \mathrm{rpm}$ the value of SN Ratio increases even further and it is noted that at speed $465 \mathrm{rpm}$ the SN Ratio has maximum value hence speed $465 \mathrm{rpm}$ is best. It also shows that when feed is changing from $0.04 \mathrm{~mm} / \mathrm{rev}$. to $0.10 \mathrm{~mm} / \mathrm{rev}$. the value of SN Ratio decreases and when feed changes from $0.10 \mathrm{~mm} / \mathrm{rev}$. to $0.80 \mathrm{~mm} / \mathrm{rev}$. the value of SN Ratio increases. It is noted that SN Ratio has max. value at feed 0.04 as shown in fig. hence feed rate $0.04 \mathrm{~mm} / \mathrm{rev}$. is best.

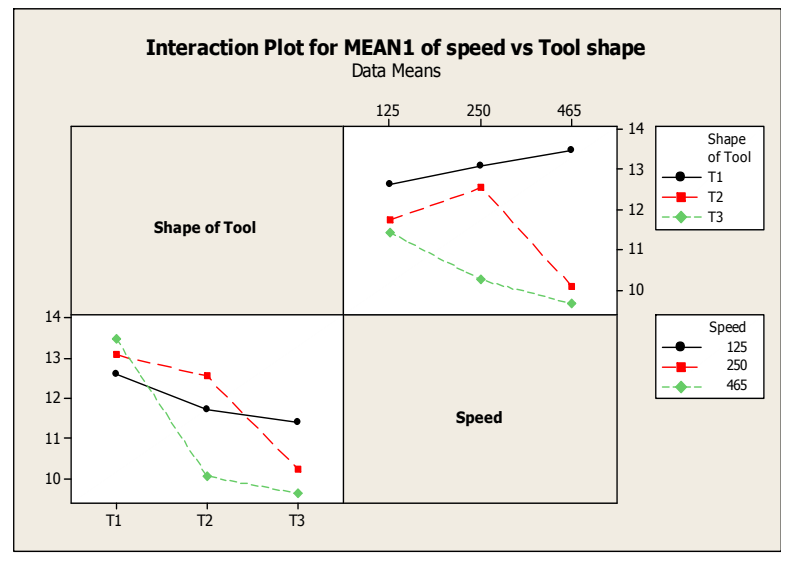

Fig.6: Interaction for mean of force, speed vs. tool shape.

The figure 6: shows that when speed changes from $125 \mathrm{rpm}$ to $250 \mathrm{rpm}$, for tool T1, feed force increases, for T2 feed force increases, while for $\mathrm{T} 3$ force decreases similarly when speed changes from $250 \mathrm{rpm}$ to $465 \mathrm{rpm}$, for tool $\mathrm{T} 1$ force increases while for tool T2 \& T3 force decreases. It is noted that from above data that tool T3 has the minimum force among three tools at $465 \mathrm{rpm}$. It also shows that when tool changes from $\mathrm{T} 1$ to $\mathrm{T} 2$, the force decreases at speed $125 \mathrm{rpm}, 250 \mathrm{rpm}$ and $465 \mathrm{rpm}$ respectively and when tool changes from T2 to T3 the force decreases at $125 \mathrm{rpm}, 250 \mathrm{rpm}$, and $465 \mathrm{rpm}$ respectively. It is concluded from the above data that the force is minimum at $465 \mathrm{rpm}$ with tool T3.

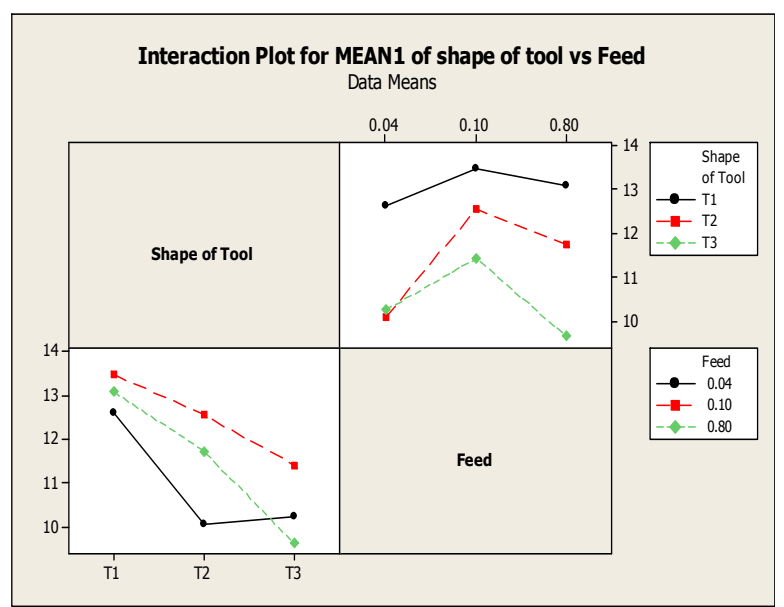

Fig.6: Interaction for mean force, shape of tool vs. feed. 
The figure 6: shows that the force increases when feed is changing from $0.04 \mathrm{~mm} / \mathrm{rev}$. to $0.10 \mathrm{~mm} / \mathrm{rev}$. for tool $\mathrm{T} 1, \mathrm{~T} 2$ and T3.and when feed is changing from $0.10 \mathrm{~mm} / \mathrm{rev}$. to 0.80 $\mathrm{mm} / \mathrm{rev}$. the forces further decreases for tool T1.T2, T3. It also shows that when tool is changing from $\mathrm{T} 1$ to $\mathrm{T} 2$, force decreases for feed rate $0.04 \mathrm{~mm} / \mathrm{rev}, 0.10 \mathrm{~mm} / \mathrm{rev} ., 0.80$ $\mathrm{mm} / \mathrm{rev}$. and when tool is further changed from T2 to T3 the force decreases for feed rate $0.10 \mathrm{~mm} / \mathrm{rev}$. and $0.80 \mathrm{~mm} / \mathrm{rev}$. but slightly increases for feed $0.04 \mathrm{~mm} / \mathrm{rev}$. It is noted that from above data in overall effect, the force is minimum at feed $0.04 \mathrm{~mm} / \mathrm{rev}$. for tool $\mathrm{T} 3$.

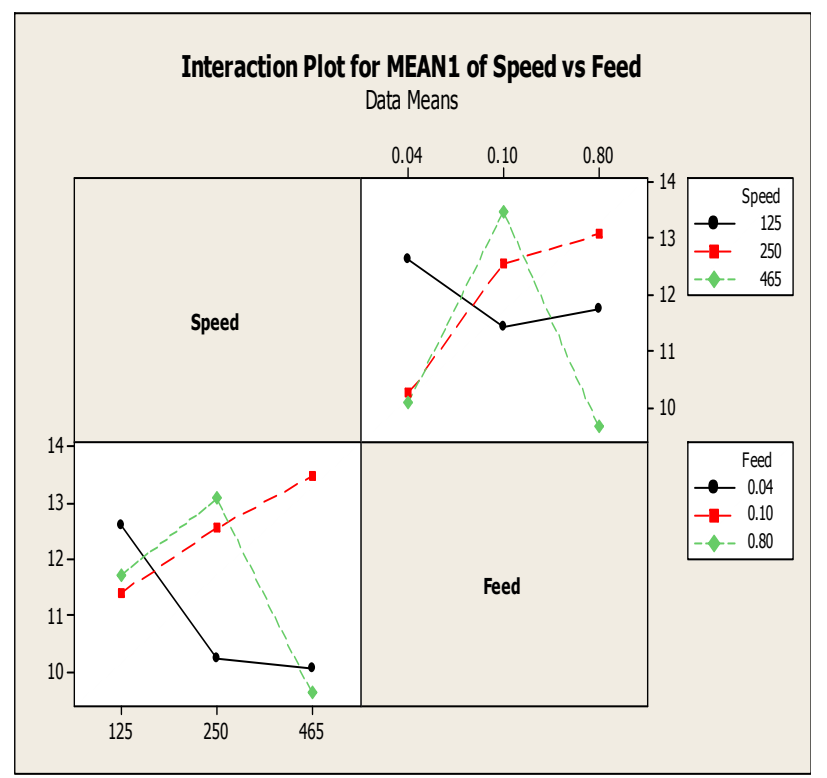

Fig. 7: Interaction for mean force of speed vs. feed.

The figure 7: shows that when feed changes from 0.04 $\mathrm{mm} / \mathrm{rev}$. to $0.10 \mathrm{~mm} / \mathrm{rev}$. the force decreases for speed 125 $\mathrm{rpm}$, and increases for speed $250 \mathrm{rpm}$ and $465 \mathrm{rpm}$ and when feed further changed from $0.10 \mathrm{~mm} / \mathrm{rev}$. to $0.80 \mathrm{~mm} / \mathrm{rev}$. the force further increased for speed $125 \mathrm{rpm}$ and $250 \mathrm{rpm}$ and it decreased very rapidly for speed $465 \mathrm{rpm}$. And hence as per the fig. speed $465 \mathrm{rpm}$ is better as force is minimum when compared with other two speeds. It also shows that when speed changes from $125 \mathrm{rpm}$ to $250 \mathrm{rpm}$ the force decreases for feed rate $0.04 \mathrm{~mm} / \mathrm{rev}$, increases for feed rate 0.10 $\mathrm{mm} / \mathrm{rev}$. and $0.80 \mathrm{~mm} / \mathrm{rev}$. and when speed is further changed from $250 \mathrm{rpm}$ to $465 \mathrm{rpm}$, the force further increases for feed rate $0.10 \mathrm{~mm} / \mathrm{rev}$. and further decreased for feed rate 0.04 $\mathrm{mm} / \mathrm{rev}$. and rapidly decreases for speed rate $0.80 \mathrm{~mm} / \mathrm{rev}$. It is concluded from above data that the force is minimum at speed $465 \mathrm{rpm}$ and at feed rate $0.04 \mathrm{~mm} / \mathrm{rev}$.
Table 5: Ranking of parameters for minimum force

\begin{tabular}{|c|c|c|c|}
\hline Level & Shape of Tool & Speed & Feed \\
\hline 1 & 22.31 & 21.52 & 20.76 \\
\hline 2 & 21.14 & 21.52 & 21.91 \\
\hline 3 & 20.34 & 20.77 & 21.13 \\
\hline Delta & 1.97 & 0.74 & 1.15 \\
\hline Rank & 1 & 3 & 2 \\
\hline
\end{tabular}

The table 5: shows the ranking of spinning parameters. It is observed from this table that delta is maximum for tool shape and minimum for speed of mandrel. This means first rank is given to shape of tool and hence shape of tool is most dominating parameter similarly speed is less dominating parameter.

\section{CONCLUSIONS}

1. It is recorded that required force is increasing from beginning and towards the outer end of sheet. Thus maximum chance of defects will be occurring at the outer end of the sheet.

2. There are shearing takes place in the sheet due to hard material of tail stock support and high rpm of machine.

3. The wrinkle defects and back flow of sheets are observed by providing feed motion manually.

4. Superior structure are observed by revolution of machine is $465 \mathrm{rpm}$ and tool feed rate of the machine is $(0.04$ $\mathrm{mm} / \mathrm{rev}$.) which are maintained with the help of coping attachment.

5. The mean of force is minimum at T3 tool at same feed and spinning speed and hence it is concluded that tool T3 (Taper roller wheel) is the best for spinning among the three tool shapes for spinning of cone or frustum of cone.

6. The mean of force minimum at speed $465 \mathrm{rpm}$ and at feed rate $0.04 \mathrm{~mm} / \mathrm{rev}$.

7. From the experimental work it is concluded that the optimum condition for spinning of cone or frustum of cone is tool T3, Speed $465 \mathrm{rpm}$, feed rate $0.04 \mathrm{~mm} / \mathrm{rev}$.

\section{REFERENCES}

[1] Brown, J., "Advanced Machining Technology", Handbook. McGraw-Hill, 1998.

[2] EamonnQuigleya, JohnMonaghanb,"Metal forming: an analysis of spinning processes", Journal of Materials Processing Technology, 2000. 
[3] Yao Jianguo, and Murata Makoto, "An experimental study on paraxial spinning of one tube end", Journal of Materials Processing Technology 128 (2002) 324-329.

[4] Chul Kim, S.Y. Jung, and J.C. Choi, "A lower upperbound solution for shear spinning of cones", International Journal of Mechanical Sciences 45 (2003) 1893-1911.

[5] Makoto Murata, Takashi Kuboki, and Tutom Murai, "Compression spinning of circular magnesium tube using heated roller tool", Journal of Materials Processing Technology 162-163 (2005) 540-545.

[6] M. Zhan, H. Yang, J.H. Zhang, Y.L. Xu, and F. Ma, "3D FEM analysis of influence of roller feed rate on forming force and quality of cone spinning", Journal of Materials Processing Technology 187-188 (2007) 486491.

[7] BAI Qian, YANG He, and ZHAN Mei, "Finite element modeling of power spinning of thin-walled shell with hoop inner rib", Transactions of Nonferrous Metals Society of chiana, 18 (2008) 6-13.

[8] Ichiro Shimizu, "Asymmetric forming of aluminum sheets by synchronous spinning", Journal of Materials Processing Technology 210 (2010) 585-592.

[9] L. Wang, and H. Long, "A study of effects of roller path profiles on tool forces and part wall thickness variation in conventional metal spinning", Journal of Materials Processing Technology 211 (2011) 21402151.

[10] Lin Wang, and Hui Long, "Investigation of material deformation in multi-pass conventional metal spinning", Materials and Design 32 (2011) 2891-2899. 